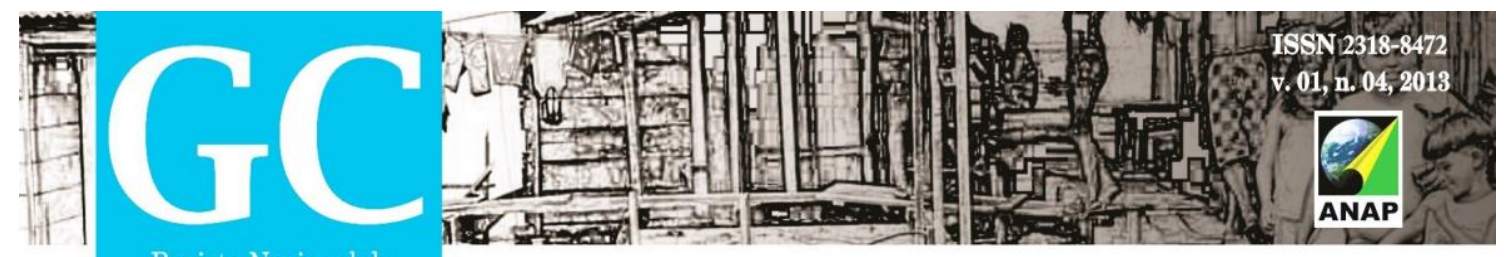

Titulo

\title{
ANÁliSE DOS ASPECTOS CONSTRUTIVOS DE PRAÇAS PÚBLICAS
}

Autora Principal

Luciana Harumi Okuyama

Coautora

Meriéli Tamiles Oliveira Albergardi

Orientadora

Jeane Aparecida Rombi de Godoy Rosin

Instituição

FACCAT - Faculdades de Ciências Contábeis e Administração de Empresas de Tupã

E-mail de contato

harumiokuyama@hotmail.com

merieli.arq@hotmail.com

Palavras-chave

Espaços públicos. Praças.

\section{INTRODUÇÃO}




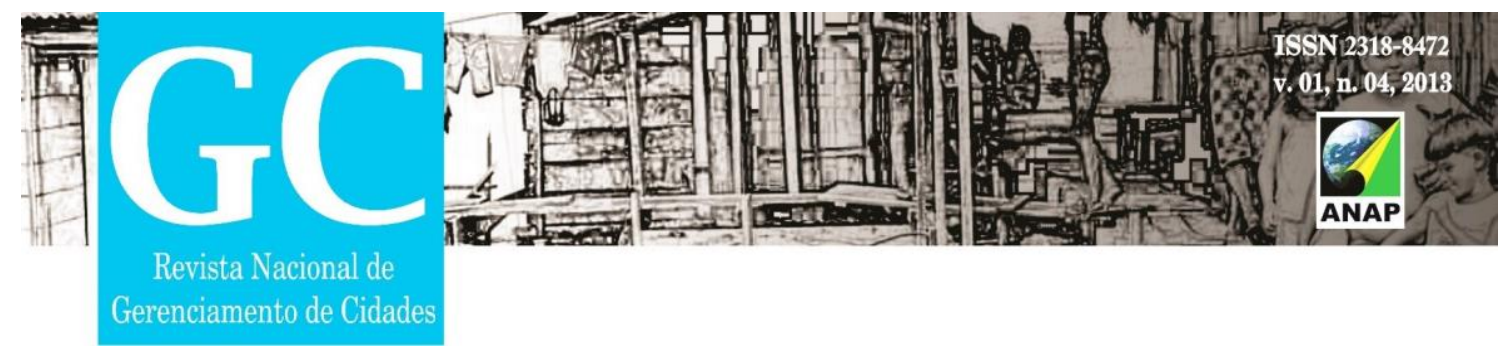

Entende-se como sendo espaços de vivência coletiva, aqueles que estão equipados, onde ocorrem eventos e/ou atividades de sociabilidade, recreio / lazer, em contexto de centralidade urbana.

No período colonial, as praças eram valorizadas e serviam como extensão das igrejas. Porém com o passar do tempo, começou-se a desvalorização desses espaços, principalmente nas periferias.

As Praças, locais públicos numa cidade, rodeadas de prédios, geralmente ajardinadas, são espaços destinados, em sua maioria, para o lazer, beneficiando os moradores e valorizando espaços, os quais desempenhava um papel importante na história, mas vêm perdendo lugar para shoppings centers, e condomínios fechados, pela falta de segurança que elas oferecem, sendo muitas das vezes abandonadas pelos órgãos públicos.

Neste estudo, tomamos como base as praças da cidade de Tupã,estado de São Paulo, onde foi adotada uma política focada em revitalizar os espaços públicos, com o propósito de beneficiar locais abandonados, por meio da implantação/ ou recuperação de praças públicas. Desse modo foram e revitalizadas os antigos espaços destinados a esse fim, com a finalidade de valorizar novamente essas áreas, tornando-as ambientes de convivência, ponto de encontro de famílias e amigos, além de possibilitar o contato com elementos do meio ambiente.

Analisando a dinâmica das praças, para entender a relação do usuário com o ambiente, o uso e apropriação do espaço, seus componentes físicos e ambientais, é possível apontar os pontos positivos e negativos proporcionado por elas. Deve-se considerar que esses espaços, são projetados para atender as necessidades dos usuários, proporcionando seu bem estar.

\section{OBJETIVO GERAL}




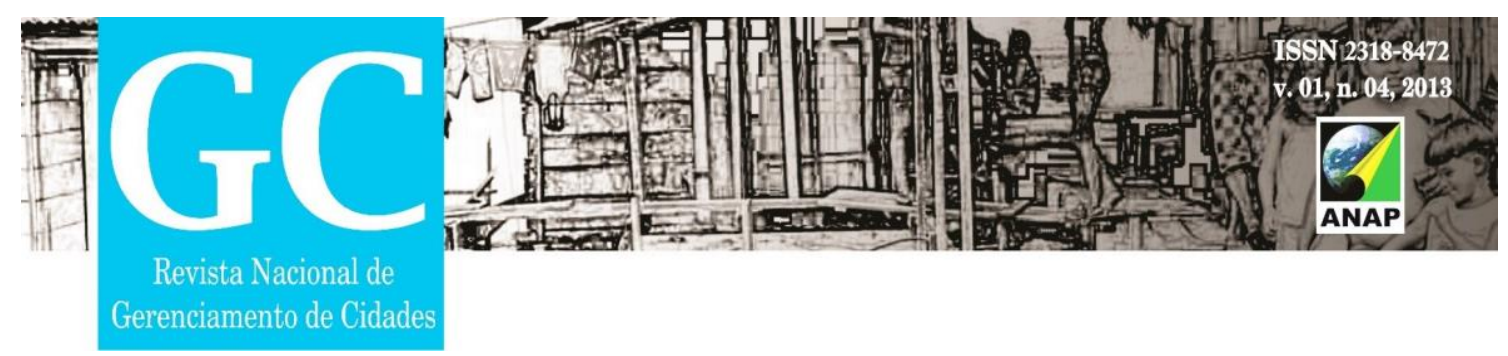

- Analisar a contribuição das praças públicas da cidade de Tupã (SP)para a melhoria da qualidade de vida de seus moradores.

\section{OBJETIVOS ESPECÍFICOS}

Analisar a contribuição dos projetos de revitalização das praças públicas, para a melhoria da qualidade dos espaços públicos, assim como para a melhoria da qualidade de vida urbana.

Para isso, toma-se como referência a cidade de Tupã, localizada no estado de São Paulo, a qual implantou recentemente, programas de revitalização dos espaços públicos, onde as praças foram as protagonistas da proposta. Com essa finalidade foram beneficiados terrenos que se encontravam em situação de abandono destinados a ocupação de praças públicas. Nesse sentido, as intervenções realizadas pelo poder público, apresentaram resultados positivos, tanto para a população residente, quanto paraa qualidade do espaço urbano em sua totalidade.

\section{METODOLOGIA}

O presente trabalho foi por meio de pesquisa documental, pesquisa bibliográfica, realizada em artigos pesquisados na internet, visando uma melhor compreensão do tema e de acordo com os conhecimentos adquiridos sobre as intervenções realizadas nas praças da cidade de Tupã.

\section{RESULTADO (S)}

Adotando como referencia para o desenvolvimento do estudo, o caso da cidade de Tupã, percebe-se as mudanças ocorridas com a reforma e construção das praças, tanto na valorização desses espaços como no 


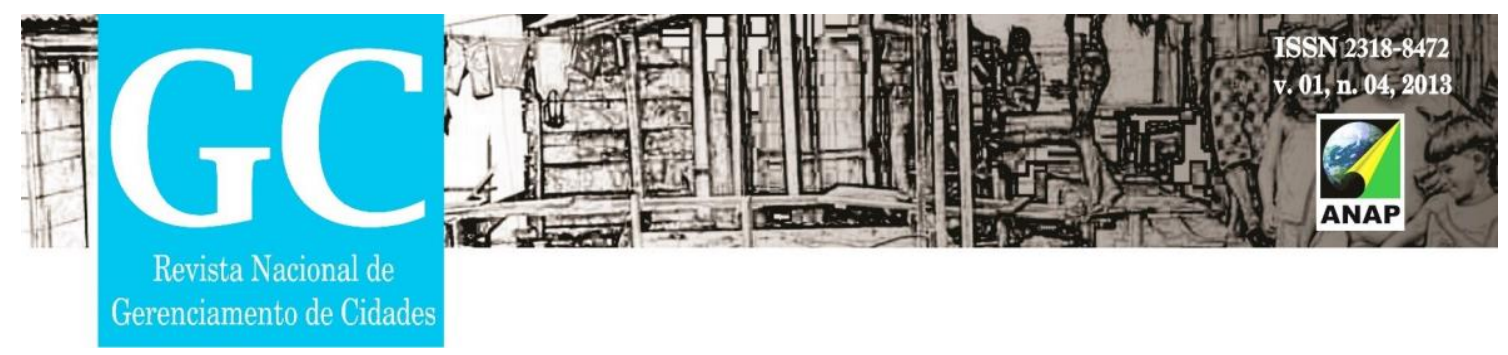

comportamento de seus usuários. Apesar de ainda haver alguns atos de depredação, a melhora no local de instalação das praças, é notável. Hoje, são espaços utilizados para reunir familiares e amigos proporcionando uma forma de lazer, além da qualidade ambiental que promovem.

A partir dessas intervenções, pode-se ressaltar a infinidade de benefícios ao se valorizar espaços urbanos com a construção de praças. Porém, a atual formatação de muitas políticas públicas, permite em diversos casos, que recursos que deveriam ser destinados a esse fim, beneficiando à população, são desviadas, em razão da precária fiscalização no processo de captação e trâmite de recursos, sem contar quando são executadas de maneira incorreta ou até mesmo abandonadas.

\section{CONSIDERAÇÕES FINAIS}

A administração pública de Tupã (gestão 2005 a 2012), investiu fortemente na construção e reforma das praças da cidade, beneficiando toda a sociedade, por meio de uma política de inclusão socioespacial, com locais de lazer, recreação ao valorizar espaços esquecidos ao longo de anos. Certamente, essas intervenções ao possibilitar novos usos nos dias atuais, acabou gerando uma integração com toda a sociedade, além de mostrar que, os espaços "fechados" (condomínios etc.), não sejam visto como área única de proteção e segurança, mas que espaços públicos também podem oferecer essas mesmas condições, ao serem dotados dos devidos equipamentos.

Portanto percebeu-se com esse trabalho, que a importante de projetos de intervenção voltados, sejam eles voltados a revitalização, requalificação ou recuperação e conservação desses locais públicos, não apenas para a qualidade do espaço urbano, mas essencialmente para a qualidade de vida de seus habitantes; 


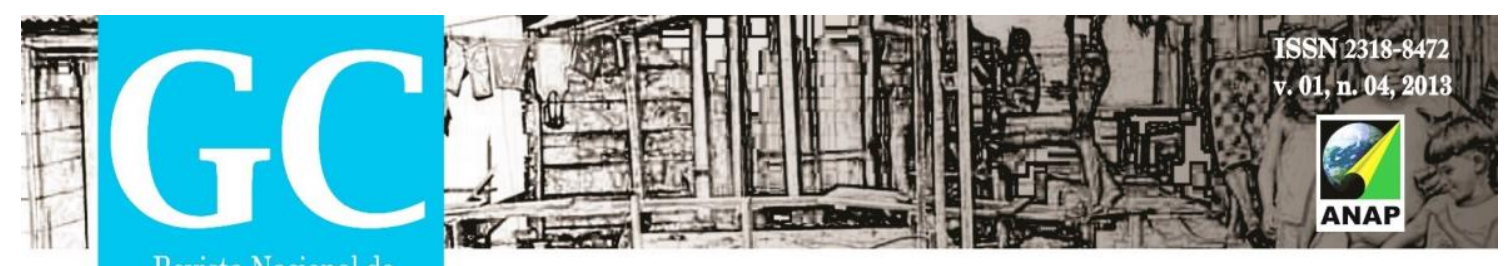

\section{REFERÊNCIAS}

CARTA MUNICIPAL DO ESPAÇO PÚBLICO: Caracterização da rede dos espaços exteriores de vivência coletiva. Disponível em: <http://www.cmodivelas.pt/extras/pdm/anexos/CMEP_Caracterizacao.pdf >. Acesso em: 16 out. 2013.

TEIXEIRA, Ítalo Filippi; SANTOS, Nara Rejane Zamberlan dos. Áreas de lazer públicas - caracterização qualitativa da cidade de Veranópolis (RS). Revista da sociedade brasileira de arborização urbana, volume 2, número 2 , 2007.

COSTIN, Cláudia; PINTO, Solon Lemos. Manual de Obras Públicas Edificações. Práticas da SEAP. Disponível em: <http://www.comprasnet.gov.br/publicacoes/manuais/manual_projeto.pdf >. Acesso em: 16 out. 2013. 